\title{
POST BELLUM
}

\author{
DOIS ARTIGOS DO PROFESSOR GIDE
}

Sobre as CONDIÇõES ECONOMICAS'e

FINANCEIRAS dos alliados após a guerra.

Acabo de receber dois interessantissimos artigos que o Professor Gide teve a gentileza de me enviar, naturalmente por haver visto meus trabalhos sobre as consequencias economicas provaveis da actual conflagração européa. O $1 .^{\circ}$ foi publicado no periodico Scientia, em Janeiro de 1917, e o 2. ${ }^{\circ}$ na Revue d'Économie Politique deste anno. A revista Scientia é, segundo creio, inteiramente desconhecida em S. Paulo, onde escrevo o presente artigo, e creio que tambem poucos leitores terá no Rio de Janeiro, pois não a pude conseguir nas livrarias onde a procurei. Quanto ao fasciculo da Revue, em que sahiu um dos primorosos artigos a que me refiro, ainda não entrou nas livrarias daqui, e portanto era com razão que, em delicada carta que me dirigiu o illustre Professor, o maior economista vivo, mostrasse elle receio de extravio dos seus preciosos folhetos na travessia do oceano. Eis porque julgo offerecer novidade digna de registro da attenção dos leitores da Revista Juridica, dando um resumo dos notaveis artigos do mestre, em assumpto que constitue preoccupação de todos quantos se interessam pelo bem estar do nosso povo e pelo dos nossos alliados, nessa tremenda lucta contra a barbaria. 
O primeiro artigo tem por titulo "La quadruple Entente économique", e, como se vê, pelo titulo, tracta precisamente da alliança, ou liga economica entre as maiores potencias que luctam com a Allemanha. Deste assumpto occupei-me em minha ultima conferencia patriotica, procurando traçar o dever de nosso povo na guerra economica contra a Allemanha, e num artigo que publiquei pelo Jornal do Brasil de 21 de Março deste anno, onde me esforcei por mostrar a vantagem de nos approximarmos economicamente dos outros povos do continente americano, e dei ao meu trabalho o titulo de "Interesse economico nas relações internacionaes". Mostra o professor, no artigo de que dou agora noticia, o que se tem dito em relação á liga das nações para formarem o Zollverein tão desejado pelos espiritos generosos. Reconhece elle que uma tão grandiosa liga, substituindo a concurrencia economica pela cooperação, seria de tal magnitude que compensaria o sangue derramado nesta guerra, uma das mais sangrentas de que ha noticia na Historia. Mas, observa, si nem mesmo com as suas colonias conseguiu a Inglaterra, mãe do free trade, realizar a união economica, si não a obteve a França, em relação ás suas, sem lhes embaraçar o desenvolvimento economico, é fóra de duvida não ser possivel tal liga entre os actuaes povos alliados, devendo ella ser, ainda por muito tempo, quiçá por muitos seculos, um doce sonho. Em proporções mais modestas, só entre os maiores, entre as quatro grandes potencias economicas, parece ao Mestre possiveI essa liga, mas em termos muito moderados. Lembra, é certo, que a Allemanha iniciou negociações com a Austria para o estabelecimento da união alfandegaria.

Mas o ponto capital do artigo é a nota de que os povos vão, de hoje em diante, se desenvolver economicamente sob a influencia do panico do bloqueio: "La crainte $d u$ blocus, voilà quelle sera l'obsession dorénavant de tous les négociateurs de traités de commerce". Foi, lisongeio- 
me em dizel-o, o ponto a que mais attenção dei no meu artigo publicado no Jornal do Brasil sobre o "Interesse economico nas relações internacionaes". Com um claro descortino do futuro, sustenta que a Belgica, pela exiguidade de seu territorio, não poderá ter a pretenção de ser sufficiente a si mesma. Não se acha, julga elle, nas mesmas condições a Inglaterra. Senhora dos mares, bem poderá se lembrar de impôr um regimen de restriçcões commerciaes a suas colonias, e portanto devemos reconhecer que estamos longe do sonhado derribamento das barreiras alfandegarias. Resumindo o artigo do economista maximo, não posso deixar de tirar algumas lições para o nosso paiz.

Diz o Mestre, logo em seguida, e na mesma ordem de idéas, que bôa é deste ponto de vista a posição da França, pois "la fortune l'a, à cet égard, assez bien servie, lui permettant de se suffire à peu près à elle même". Si a França póde produzir tudo o que consome, que diremos do Brasil, que tem todas as temperaturas desejaveis, desde a torrida do Amazonas, onde é produzida a borracha, até a do Rio Grande do Sul, onde temos o trigo e a vinha? Cessada a confiança na paz, por força da conflagração, forçados os povos pela Allemanha a só confiarem em sua espada prompta a ser desembainhada para defesa de seu logar ao sol, indispensavel se torna que pensemos em nossa independencia economica, sem prejuizo das vantagens da divisão do trabalho, que regula mesmo as relações economicas internacionaes, mantendo neste assumpto, um justo equilibrio, e (queiram os que me honram, lendo este artigo meditar longamente sobre isto), mais do que nunca, procuremois estreitar nossos laços de amizade e de commercio entre os diversos Estados do Brasil, e entre os paizes do Novo Continente. Si o riquissimo S. Paulo, não tiver o sentimento de fraternidade para com o Ceará, economicamente inferior, lem- 
bre-se de que precisará deste para a lucta externa; si não for S. Paulo arrastado a manter a União Federal pelo amor ás tradições de nossa patria, mova-se pelo interesse... Falo apenas em hypothese, porque estou certo de que ainda ha, em nossos peitos, bastante patriotismo, para não pensarmos em desmembrar nossa patria, separando irmãos por um interesse mal entendido. Mas... o patriotismo ia me fazendo esquecer o que me propuz neste artigo: dar conta de dois artigos do notavel economista Professor Gide. Diz elle ser possivel entre os paizes amigos certas protecções alfandegarias, de modo a facilitar-se a entrada de algumas materias primas, dando aos alliados superioridade sobre a Allemanha na producção de não poucos artigos, e nisto póde consistir toda a cooperação dos alliados, si quizerem proteger-se após a guerra.

$\mathrm{Na}$ segunda parte de seu artigo não mais se occupa com o auxilio reciproco que se devem prestar os alliados, mas com a guerra que elles poderão fazer á Allemanha no campo economico, denominando a primeira parte a positiva, e a segunda a negativa. Occupa-se então com a boycottagem dos productos allemães, pedida, não pelo povo, pela gente ignorante, pelos leigos em Economia Politica, mas até por pessoas de relativa cultura, entre as quaes menciona os membros de diversas ligas patrioticas em França, Carson, membro da Camara dos Communs na Inglaterra, e Hughes, primeiro ministro na Australia. E' o que o grande economista contesta possa ser feito com vantagem. Põe diante de nossos olhos, em primeiro logar, a necessidade, pois a França necessita de certas materias primas que só a Allemanha lhe poderá fornecer, bem como de certos productos semi fabricados, sem o que é difficil o andamento de sua industria. Esclarecerei o que ha em relação a esta ultima necessidade. Quasi toda a gente alheia ás industrias ignora que certos productos são começados em um fabricante, e terminados em outro, por 
vezes de outro paiz. Os queijos "Rocquefort" são feitos por pobres camponezes, e curados ou raffinés por uma poderosa companhia. São as navalhas com frequencias começadas em um paiz e terminadas em outro. Tambem é commum, e vemos nas proprias caixas dellas, que o fabricante tenha a mina de producção do aço em um paiz e a fabrica em cutro, e assim vemos uma alliança economica entre Hamburgo e Sheffield. Eis o que são "produits serni-fabriqués indispensables à la marche de nos industries" de que fala Gide. Accrescente-se-a todas essas considerações, a feita pelo Mestre de que não se criam em um dia industrias novas, e os que não sabem scientificamente o alcance da verdade, sentirão quanto é ella importante, ao notar, no mercado brasileiro, a falta de anilinas e de certos productos chimicos, só produzidos pela Allemanha. Os alliados chegarão á perfeição neste ramo de industria, mas não em um dia, e sim após dezenas de annos.

Passa o economista ao segundo motivo por que é impossivel a boycottagem. E' a difficuldade em que ficariam os paizes alliados por diminuição de sua renda alfandegaria, motivo de grande peso contra a boycottagem, diz o previdente economista, attendendo-se ao aperto em que se acharão, empós a guerra, os paizes belligerantes: si os amigos não pagarem por concessão de amizade, e si os inimigos não entrarem com seus productos, e portanto não forem forçados ao pagamento dos impostos nas alfandegas, que restará ao Estado? Considera elle mais forte de todas a terceira razão contra a boycottagem internacional: si nada comprarmos aos austro-allemães, tambem nada lhes venderemos, não porque adoptem elles uma medida de retorsão, mas por uma lei economica, conhecida do mais modesto estudante, lei que affirma que, quando os valores da importação oessam, suspende-se, tambem a exportação. Ora, diz o genial Professor, os belli- 
gerantes "auront après la guerre, un besoin urgent d'exporter le plus possible, d'exporter à tout prix, car ce sera le seul moyen de faire revenir l'or, de faire remonter le change..." Transcrevo as proprias palavras do Professor, para que vejam meus patricios o vigor com que fala elle da necessidade de produzir e exportar após a guerra. $O$ que julga o Professor acertado é exportar o. mais possivel, para os neutros, e mesmo para os inimigos; e é isto o que constitue, diz elle com superioridade, a guerra economica offensiva, a invasão e a conquista do territorio inimigo.

Emfim condemna o economista o plano official em França de evitar o dumping dos inimigos, sendo o dumping, como sabem os industriaes, ter um preço maior para os nacionaes e outro menor para os estrangeiros, processo pelo qual se conquista um mercado estrangeiro. $\mathrm{O}$ dumping será, diz elle, feito por todos os povos, apenas cesse a lucta sangrenta e contra elle serão inefficazes as medidas que forem tomadas pelos poderes publicos.

No fecho do artigo de que ora me occupo, está o que mais interessa, e vem a ser a possibilidade de, por um appello aos nobres sentimentos de patriotismo, conseguir a quadrupla liga (Inglaterra, Belgica, Italia e França) não comprem dos allemães os cidadãos dos paizes alliados sinão o que não puderem conseguir dos paizes amigos. Moço, como sou, entretanto, julgo ser eu menos crente do que o Professor Gide, pois o que tenho visto em nosso paiz e o que a Historia me ensina é o condemnavel esquecimento das atrocidades practicadas contra os nossos concidadãos. Em minha ultima conferencia patriotica, já manifestei a pouca confiança que deposito neste sentimento natural em todo homem realmente patriota. Lembrei mesmo aos meus concidadãos que Roma devêra sua grandeza a não esquecer nunca as affrontas de seus ini- 
migos, e vingal-as inexoravelmente, embora feitas em épocas remotas e a gerações desapparecidas, desde muito, da face do territorio romano, e citei exemplos tirados de Cesar, em seus Commentarios sobre a Guerra das Gallias: "Y penser toujours, n'en parler jamais" é uma optima politica, supponho eu, mas que difficilmente obteremos, si todos os povos se assemelharem ao brasileiro, que é a antithese do povo rancoroso. Fecha-se o artigo, lembrando Gide que Yves Guyot propoz a suppressão dos direitos aduaneiros por parte da Allemanha, no tratado de paz; e que Norman Angel propoz o desarmamento e o arbitramento obrigatorio, o que corresponideria á renuncia á guerra sangrenta como condição para cessar a guerra commercial. Tudo isto é muito difficil de se obter, e, dando noticia do primeiro artigo do Professor, direi, em resumo, que, por elle, fiquei mais firme na opinião de que uma guerra economica, é certo, será feita após a guerra sangrenta, e que ella muito mais difficil é de ser dirigida pelos poderes publicos do que se pensa geralmente. E' provavel seja ella d'esordenada ou rebelde á acção dos poderes publicos, e sustentada e dirigida só pelas forças naturaes.

$\mathrm{E}$ ' isto de esperar, porque, nos tempos modernos, o Governo é, as mais das vezes, occupado pelos incompetentes, sendo a entrega da direcção dos destinos de um Estado aos intellectuaes uma excepção, que só occorre nos momentos de perigo. Si os alliados têm hoje no Governo Woodrow Wilson, Clemenceau, Nitti, Victor Emmanuel Orlando, é que os povos que hoje se batem não confiam no pessoal que antes, com pouca competencia, dirigia os mais importantes Estados do mundo. Ha poucos dias, um grande sabio brasileiro, o Dr. Luiz Barreto, dizia, acompanhando a opinião de Augusto Comte de quem é ardente adepto, ser o periodo actual de transição. Praza aos Céos que assim seja. 
Tornemos, porém, a pensamentear sobre o que succederá quando fôr finda a guerra. Suppõe o Professor Gide que "o sangue de miss Cavell, do capitão Fryat e de tantos belgas e franceses innocentes, nodoarão os pro¿ductos allemães com uma marca indelevel - Made in Germany." Logo accrescenta: "E' possivel que, com o tem. po, ella se apague..." Como se vê, o Professor julga difficil prognosticar qualquer coisa em tão melindroso caso. Peço licença ao Mestre e aos que me lêem, para transcrever um trecho de minha ultima conferencia, na qual me occupei com a guerra encarada do ponto de vista economico, apresentando o trecho onde affirmei, sem ambages, achar-se isto acima da faculdade de prever que temos dentro de certo limite, ou com alguma probabilidade de acerto. Eis a parte dessa conferencia, na qual tantas vezes citei o emerito economista: "Será possivel a lucta economica mesmo depois de cessada a lucta pelos canhões? Depende essa nova guerra de certos elementos que não podemos agora prever si permanecerão, quando se desfizer a ultima fumaça do derradeiro tiro. Era necessario que o povo inteiro, todos os commerciantes e mesmo os individuos que compram para seu uso pessoal, conservassem para com a Allemanha o mesmo odio que hoje têm. Esse phenomeno não se dará provavelmente e, ainda em relação aos judeus, não obstante o factor religioso, esse odio não foi bastante para os privar de clientes. Por algum tempo, sin, os allemães terão de nós alguma coisa mais do que a antipathia. E' de referir que os rancores antigos não eram tão accentuados após as guerras externas, quanto depois das civis, e serão muito maiores após as actuaes, em que é envolvida toda a nação, e não sómente um exercito de profissionaes. E' a nação inteira que se bate hoje na guerra externa, como o foi sempre na civil. A guerra gera feridas incuraveis nas classes que foram mais martyrịzadas por ella, e, quando ataca toda a nação em todas 
as classes, deixa vestigios em todas as almas. Conta-se que Curupaity, foi a batalha em que, por circumstancias particulares, pereceu a flôr da nobreza argentina. Durante muitos annos, não se podia pronunciar esse nome em um ssalão argentino, sem que uma lagrima de dôr pungente, de saudade infinda, deixasse de rolar nas faces aristocraticas de uma dama. E no emtanto não foi mais mortifera. que tantas outras pugnas, em que as nossas armas, unidas ás dos nossos valentes alliados, deixaram escriptas, com o sangue de nossos avós, a brilhante epopéa que se chamou Guerra do Paraguay... War after war é pois coisa. muito duvidosa."

$$
\text { * } *
$$

Tracta de assumpto muito mais difficil o segundo artigo, pois que se occupa do meio circulante, á luz dos principios da Sciencia das Finanças, e por isso é subordinado ao titulo de "Entente Financière". Alludindo fugidiamente aos projectos de reorganização dos povos, que, como sabem os versados em Direito das Gentes, formaram duas escolas, a diplomatica e a juridica, diz que estão na "bruma das hypotheses", merecendo, por emquanto, estudo sómente as ligas. Dessas, ha a colonial, a financeira, a economica e a politica. E' da financeira que tracta o Mestre neste interessantissimo e recentissimo artigo com que vamos occupar nossa attenção. Na primeira parte do artigo, tracta do modo de repartir as despezas da guerra, materia que quasi nada nos interessa, porque, como diz o Professor, devem os paizes da America do Sul ser della excluidos, por terem tido insignificantes despezas com a conflagração. Entende que, desde que ha um só commando, uma só frente, um unico generalissimo, uma causa unica, unica deve ser a bolsa, e consequentemente cumpre se repartam as despezas proporcionalmente, como si todos os quatro povos alliados formassem um unico Estado em 
guerra. Em tal divisão, seria a França, que mais soffreu com a guerra, a mais favorecida das quatro potencias, e os Estados Unidos a nação menos aquinhoada, por ter sido a que menos perdeu. Comquanto justissima esta fórma de divisão, diz o escrupuloso Professor que, de algum outro modo, que não só a lembrança de Lafayette, poderia bem a França mostrar sua gratidão á America do Norte, e lembra a cessão de Guadalupe, Martinica, Goyana e São Pedro e Michelon, quiçá mesmo Taiti.

A segunda parte do artigo é de muito mais alcance economico. Dada a impossibilidade de ser acceita a primeira fórma de repartição das despezas, carregando cada paiz com as proprias despezas, o que parece ao Professor e a nós injusto, ha a idéa de solidarizar uma emissão, para fazer face a taes despezas, ou, noutros termos, deverão se constituir os alliados de hoje fiadores reciprocos de um grande emprestimo internacional. Nota o Professor apenas a difficuldade da fiscalização contra o que denominamos em Economia Politica a "inflação", que é c excesso na emissão do papel moeda, fiscalização quasi impossivel, pois viria ferir a susceptibilidade da liga financeira. Neste ponto, devo fazer umas breves considerações, desenvolvendo as idéas do grande economista sobre papel moeda internacional.

Em uma bellissima carta, com que me honrou o Dr. Felix Rodrigues, a pedido do grande Mestre, fez-me sentir, referindo-se a um artigo que publiquei no Jornal do Commercio, do Rio, a 25 de Dezembro do anno passado, ter sido eu omisso na parte relativa á funcção possivel do papel moeda nas relações internacionaes. Perfeitamente praticavel é a moeda inconversivel internacional, e, emi época que não podemos fixar já, será ella uma realidade, vencidos os embaraços, como é o apontado pelo Professor, o da fiscalização. A carta que me dirigiu o Dr. Felix Rodrigues, confirmada por uma outra autogra- 
pha do Mestre já se acha na redacção de um grande jornal, que seguramente a publicará dentro em pouco. Este projecto de liga internacional para a emissão de um unico papel moeda, como diz o emerito economista, teria a grande vantagem de cultivar o mutualismo entre os povos, fazendo que sintam elles os beneficos effeitos da solidariedade.

Continúa, porém, o genial economista e financeiro, notando que todos esses projectos teriam como unico resultado alliviar os povos belligerantes de parte do peso das despezas da guerra, mas que ainda muita responsabilidade economica lhes ficará, mesmo si forem realizadas essas medidas hoje projectadas. Como acudir ao resto do encargo? Ahi temos, dentre os planos varios, os dois, que mais suffragios alcançaram, comquanto não pareçam ao grande financeiro dos mais viaveis. Entramos na parte mais delicada e mais technica do estudo do profundo financeiro. $\mathrm{O}$ primeiro projecto, que é o de Citroen, propõe a criação de um "Banco das Nações", emittindo papel pela unidade monetaria "Simplex". Emittirá um certo numero de milhões de francos, pela unidade nova, equivalente a 1,03 do franco, ou a um terço de gramma de ouro. Esse dinheiro será distribuido pelas nações belligerantes, de accôrdo com as suas necessidades. As consequencias serão que, não podendo os indemnizados com esse papel adquirir valores moveis, ou titulos hoje existentes, porque estes subirão vertiginosamente, virão a fomentar industrias novas, como succede, quando ha inflação de papel moeda, e dahi "uma prosperidade industrial sem precedentes", diz Citroen, e repete maliciosamente Gide, sublinhando a phrase, e accrescentando que acha a solução excessivamente simplicista. (E quantos financeiros não ha da força de Citroen, mesmo em nosso querido Brasil!...) A consequencia deste projecto, que não passa de uma inundação de papel moeda, será diz Gide, 
"précipiter la valeur de l'or bien au dessous de celle de l'argent". Um erro enorme de Citroen, como diz o Professor, é pensar que as industrias absorvem dinheiro, do mesmo modo porque a esponja absorve os liquidos: " $O$ dinheiro que passa das mãos do que o empresta ás do que o recebe, continúa a existir, com a differença unica de que será empregado em compra de materias primas, salarios, em logar de ser empregado em consumo pessoal". Ao terminar a critica do projecto, Citroen, insinúa o Mestre que é de suppôr tenham as cedulas a mesma sorte de certas peças metallicas que procuramos passar rapidamente por nos parecerem duvidosas.

Occupa-se depois com o projecto Mauricio Duclos, que, diz elle, não differe essencialmente do já exposto, a não ser na unidade monetaria, de um terço de gramma de ouro no anterior, e de um kilogramma no de Mauricio Duclos. Esses projectos que o Mestre dá claramente a entender que são irrealizaveis, não nos interessam muito. Interessa-nos, porém, o estudo das bases em que se assentam. Mostrando o Mestre que o fundamento attribuido aos titulos por Duclos constitue um circulo vicioso, pois que afinal o que affirma o imaginoso criador do systema é que o "bilhete internacional terá por garantia o seu poder de compra", julga acceitavel o que sustenta Citroen, quando diz: "A guerra mostrou ser possivel emittir, sem lastro. de ouro, uma certa quantidade de bilhetes de banco, cujo valor fosse fundado no crédito dos paizes emissores". Ahi temos o papel moeda em toda sua pureza, e aproveita o genial economista a opportunidade, para, em uma pagina de extraordinaria concisão, resumir toda a sua theoria do papel moeda. Eis esse trabalho, notavel pela clareza, pelo laconismo e pela profundeza de vistas de um homem que liga os conhecimentos economicos aos psychologicos. "Poder-se-ia até dizer que a guerra não fez mais do que pôr em evidencia o que existia já em tempo de paz, a saber que, mesmo quando resgatavel em 
especies, a nota bancaria tira seu valor do credito, ou mais exactamente do consenso universal para a acceitar como instrumento de troca, e de liberação pelo valor inscripto nella. Com excepção dos banqueiros, que têm necessidade de ouro para remessas para fóra, não occorre a ninguem, ao receber uma nota bancaria, ir leval-a ao banco, pará saber si é reembolsavel, nem mesmo para fazer dinheiro, porque seria mais facil trocal-a no primeiro estanque de tabaco: a nota é por nós acceita, porque sabemos que todo o mundo a acceitará, do mesmo modo que nós a acceitámos.

Digamos mais: a moeda de ouro deve seu valor muito menos ao metal de que é feita, do que ao algarismo de seu valor, que ella traz gravado, e que lhe serve de passaporte. Seu valor não é menos convencional do que o da nota, porque, si ella viesse a ser fundida, sem conservar mais que seu valor industrial, veria o portador derreter-se este valor entre seus dedos, como si fosse um floco de neve. E, si o valor da moeda de ouro é mais solido do que o da nota, não é precisamente porque ella é de ouro, mas porque o consentimento mutuo, sobre o qual elle se funda, não é o de quarenta milhões de franceses, mas o mundo inteiro, é porque seu valor é internacional, e não sómente nacional. Consequentemente toda nota que, do mesmo modo que o simplex, tivesse curso leqal, e effectivo em todos os paizes civilizados, teria a mesma vantagem, mas com a condição de não exceder a quantidade emittida ás necessidades.

Porquanto, si estamos dispostos a crer, com os autores desses projectos, que o valor do bilhete póde se manter independente de uma garantia material, não podemos admittir que seu valor se manteria não obstante uma emissão illimitada. Não confundamos essas duas theses..." No artigo que, a 25 de Dezembro passado, publiquei no Jornal do Commercio, do Rio, fiz sentir que a superioridade actual do ouro estava em tornar impos- 
sivel a inflação, porque representa elle de facto com grande exactidão o capital existente, ou a riqueza poupada ao consumo. Era minha intenção mostrar o perigo da inflação. Na carta que, da parte do genial economista, me foi dirigida, fazia-me elle notar, comó acima disse eu, a omissão que houve em meu artigo da referencia ao papel moeda internacional, omissão que ora corrijo, transcrevendo essa bellissima pagina do Mestre, sobre a qual seria patriotico meditassem todos os homens que podem influir nos destinos economicos do nosso querido Brasil. Não para me vangloriar, mas para proveito de nossa patria, direi que o Mestre elogiou o que eu dissera sobre a alta comprehensão de Ruy Barbosa e de Murtinho, em relação ao papel moeda no Brasil. Bem empregado, usado com prudencia, é elle um instrumento de progresso economico valiosissimo, a que deve a America seu desenvolvimento, não passando realmente o ouro, como diz o genial economista na carta que me dirigiu o Dr. Felix Rodrigues, de um metal não precioso, mas covarde, pois foge nos momentos de perigo, quando a crise apavora um paiz.

O final da terceira parte do trabalho de que me occupo é verdadeiramente grandioso. Traz-nos á lembrança um trecho das Narrações do Infinito, de Camillo Flammarion. Declarando que não é ministro da fazenda, nem director de banco, desfere o Professor seu vôo de homem de genio, e, com sua imaginação poderosissima, mostra que a provavel e natural queda da moeda após a guerra, não é mais que um episodio na depreciação em geral, lenta e constante da moeda de que nos dá noticia, ou que regista a Historia: "o franco de nossos dias não vale um soldo do tempo de Carlos Magno". Essa queda do valor a que se acha sujeita a moeda é continua, mas, em geral, quasi imperceptivel, tendo entretanto momentos em que excepcionalmente se dá até vertiginosamente, como no caso da descoberta da America. Outra convulsão mo- 
netaria poderá occorrer em seguida á guerra, e será, em todo caso, uma liquidação. E' pois uma crise provavel que nos prenuncia o genial economista, e, em um meu artigo, que tive a honra de ver publicado nesta Revista, mostrei as dores a que está sujeito um povo onde surgem taes convulsões. Qual será a liquidação produzida por esse parto laborioso?...

$$
\text { * }
$$

Vejamos como encerra o Mestre seu artigo, e quaes as medidas que propõe para uma liquidação, quanto possivel, pacifica. E' o papel moeda com curso internacional, e rodeado de todas as cautelas, ao intento de evitar a inflação, o recurso unico, que parece possivel ao maestro di color che sanno.

Ah! si depois da guerra, fossem as pastas da Fazenda confiadas a Ruy Barbosa, a Gide, a Nitti e a outros raros astros de primeira grandeza que brilhàm no firmamento do Brasil, da França e da Italia, quão facil seria enfrentar a crise provavel!... Infelizmente isto não succederá: é raro que taes encargos caibam a um Murtinho, a um Ruy... Aos ministros menos versados em Sciencia das Finanças, peço, em nome de minha patria, muita prudencia. Referir-lhes-ei um facto que profundamente me impressionou. Conheci um medico de pouco preparo scientifico, mas muito consciencioso. Perguntei-lhe eu por que motivo não usava dos alcaloides, nem das injecções hypodermicas. Respondeu-me que o clinico trata, as mais das vezes, ás apalpadelas, empiricamente, e que, assim sendo, o systema de applicar os medicamentos pela via gastrica offerece mais segurança, pois vae o medico observando o effeito produzido, que é sempre lento; ao passo que, com a violencia dos alcaloides e das injecções hypodermicas, quando o clinico dá pelo erro, é tarde. Appli- 
cando o conto, direi que aconselho aos menos versados nas leis que regem os phenomenos economicos, tenham muita cautela com o papel moeda, instrumento delicadissimo, de effeitos beneficos, quasi miraculosos, nas mãos de um Ruy, de um Gide, mas uma calamidade, uma praga, nas de um sarrafaçal, de um politico guindado ás alturas do poder... pela intriga...

Braz de Sousa Arruda,

Docente da Faculdade. 